PEREIRA AS; BERTONCINI O; CASTRO CM; MELO PE de; MEDEIROS CAB; HIRANO E; GOMES CB; TREPTOW RO; LOPES CA; NAZARENO NXR; MACHADO CMM; BUSO JA; OLIVEIRA RP; UENO B. 2010. BRS Ana: cultivar de batata de duplo propósito. Horticultura Brasileira 28: $500-505$.

\title{
BRS Ana: cultivar de batata de duplo propósito
}

\author{
Arione da S Pereira'; ${ }^{1}$ Odone Bertoncini' ${ }^{2}$; Caroline M Castro ${ }^{1}$; Paulo Eduardo de Melo ${ }^{3}$; Carlos Alberto \\ B Medeiros ${ }^{1}$; Élcio Hirano ${ }^{2}$; César B Gomes ${ }^{1}$; Rosa O Treptow ${ }^{4}$; Carlos Alberto Lopes ${ }^{3}$; Nilceu XR Naza- \\ reno $^{5}$; Cristina Maria M Machado ${ }^{3}$; José Amauri Buso ${ }^{3}$; Roberto P de Oliveira ${ }^{1}$; Bernardo Ueno ${ }^{1}$ \\ ${ }^{1}$ Embrapa Clima Temperado, C. Postal 403, 96001-970 Pelotas-RS; ${ }^{2}$ Embrapa Transferência de Tecnologia, EN-Canoinhas, C. Postal \\ 317, 89460-000 Canoinhas-SC; ${ }^{3}$ Embrapa Hortaliças, C. Postal 218, 70351-970 Brasília-DF; ${ }^{4}$ UFPEL-FCD, Dep ${ }^{\text {to }}$ Ciência dos Alimentos, \\ C. Postal 354, 96010-900 Pelotas-RS; ${ }^{5}$ Iapar-Pólo Regional de Pesquisa de Curitiba, R. Máximo João Kopp 274, Centro Administrativo \\ do Governo do Estado do Paraná, Santa Cândida, 80630-900 Curitiba-PR; arione@cpact.embrapa.br
}

\section{RESUMO}

O genótipo BRS Ana é uma nova cultivar de batata adequada para fritura à francesa, com potencial de processamento na forma de palitos pré-fritos congelados e de flocos, liberada em 2007. Foi desenvolvida pelo Programa de Melhoramento de Batata da Embrapa (Clima Temperado, Pelotas-RS, Transferência de Tecnologia - Escritório de Canoinhas-SC e Hortaliças, Brasília-DF), com base na aparência e rendimento de tubérculos, peso específico e qualidade de fritura. Os tubérculos têm película vermelha, levemente áspera, polpa branca, formato oval e olhos rasos. O potencial produtivo é alto. No ecossistema subtropical, apresentou maior produtividade $(31,2 \mathrm{t}$ $\left.\mathrm{ha}^{-1}\right)$ que as cultivares mais plantadas no país, quando cultivada no outono, e não diferiu na primavera. Em ecossistema tropical, plantio da seca, a cultivar BRS Ana foi tão produtiva $\left(33,8 \mathrm{tha}^{-1}\right)$ quanto as demais cultivares avaliadas. Produziu maior percentagem de tubérculos graúdos $(55,6 \%)$ e peso médio dos tubérculos $(108,4 \mathrm{~g})$ que as testemunhas no outono do ecossistema subtropical. Em ambos os ecossistemas, a cultivar BRS Ana apresentou elevados valores de peso específico $(1,086)$ e conteúdo de matéria seca $(19,7 \%)$. Nos testes sensoriais mostrou-se adequada à fritura na forma de palitos, tanto no preparo doméstico, quanto na industrialização. É moderadamente suscetível à requeima (Phytophthora infestans) e tem boa resistência à pinta-preta (Alternaria solani). A reação à podridão-mole (Pectobacterium sp.) é similar à das cultivares mais plantadas. Apresenta baixa degenerescência de sementes por viroses, conferida pela resistência moderadamente alta ao PVY e baixa incidência do PLRV. Suscetibilidade a distúrbios de origem fisiológica nos tubérculos não tem sido observada. No ecossistema subtropical a tuberização é mais tardia na primavera, devendo portanto ser plantada mais cedo.

Palavras-chave: Solanum tuberosum L., cultivar, melhoramento genético.

\section{ABSTRACT}

\section{BRS ANA: A dual purpose potato cultivar}

The genotype BRS Ana is a new potato cultivar adequate for French fries, with potential for processing into frozen French fries and flakes, released in 2007. It was developed by the Embrapa Potato Breeding Program (Embrapa Temperate Agriculture, Pelotas-RS; Embrapa Transference of Technology, Office of Canoinhas-SC; and Embrapa Vegetables, Brasília-DF), based on tuber appearance and yield, specific gravity and French fries quality. Tubers are redskinned, lightly rough, oval shaped with shallow eyes. The pulp is white. Cultivar BRS Ana has high yield potential. In the subtropical ecosystem, cultivar BRS Ana showed higher yield (31.2 $\left.\mathrm{tha}^{-1}\right)$ than the most used cultivars in Brazil when grown in autumn, and did not differ from them in the spring. In the tropical ecosystem, under irrigation, BRS Ana did not differ from both control cultivars. It produced higher percentage of marketable tubers (55.6\%) and average tuber weight $(108.4 \mathrm{~g}$ ) than the controls in the fall crop of subtropical ecosystem. In both ecosystems, cultivar BRS Ana presented high specific gravity (1.086) and dry matter content (19.7\%). The sensorial analysis showed that cultivar BRS Ana is adequate for home made French fries as well as for industrial processing. It is moderately susceptible to late blight (Phytophthora infestans) and presents good resistance to early blight (Alternaria solani). The reaction to the tuber soft rot (Pectobacterium sp.) is similar to the most used cultivars. It has low seed degeneration conferred by moderate resistance to PVY and low incidence of PLRV. Susceptibility to tuber physiological disorders has not been observed. It seems that BRS Ana has lower fertilizer and water requirements than the most planted cultivars, meaning reduction of crop cost and risk. In the subtropical ecosystem, tuberization starts later in spring, therefore BRS Ana should be planted earlier in the season.

Keywords: Solanum tuberosum, cultivar, breeding.

(Recebido para publicação em 3 de março de 2010; aceito em 5 de novembro de 2010) (Received on March 3, 2010; accepted on November 5, 2010)

$\mathrm{O}$ genótipo BRS Ana é um produto do Programa de Melhoramento Genético da Embrapa formado pela Embrapa Clima Temperado, Pelotas-RS, Embrapa Transferência de Tecnologia -
Escritório de Canoinhas-SC e Embrapa Hortaliças, Brasília-DF, que foi liberado em 2007. A cultivar BRS Ana foi derivada de um cruzamento entre o clone C-1750-15-95 (progenitor feminino) e a cultivar holandesa Asterix (progenitor masculino) (Figura 1), efetuado em casa de vegetação, na Embrapa Clima Temperado, no ano 2000. O clone C-1750-15-95 foi selecionado do cru- 


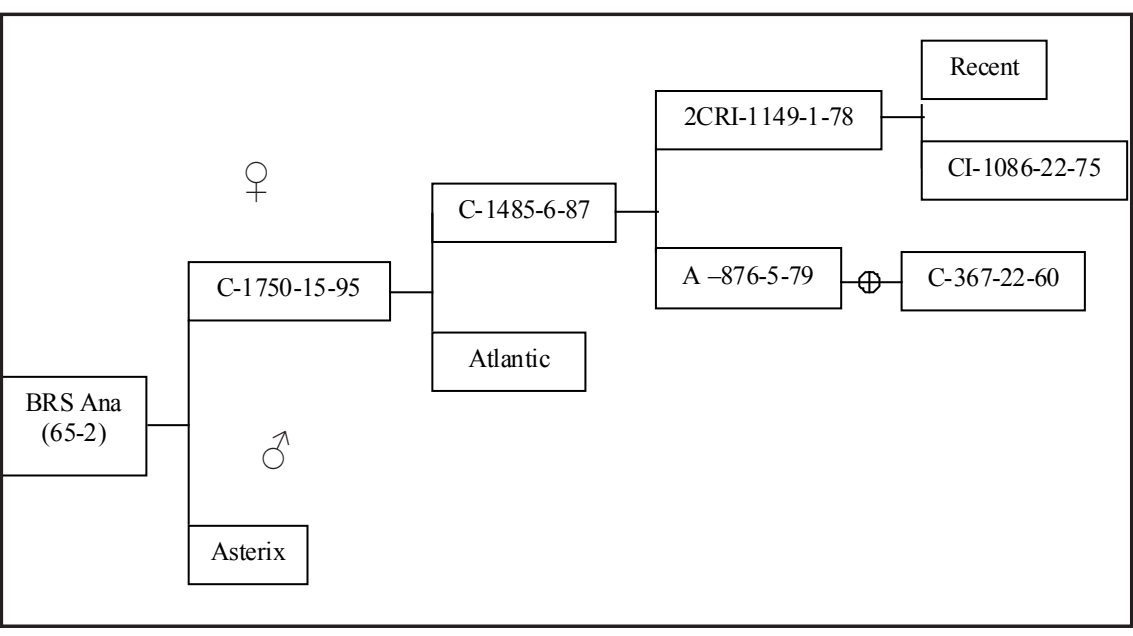

Figura 1. Genealogia da cultivar BRS Ana (pedigree of cultivar BRS Ana). Pelotas, Embrapa Clima Temperado, 2010.

zamento entre o clone C-1485-6-87 e a cultivar norte americana Atlantic. $\mathrm{O}$ clone C-1485-6-87 foi derivado do cruzamento entre dois clones selecionados na Embrapa, 2CRI-1149-1-78 e A-876579. O primeiro foi obtido do cruzamento entre a cultivar holandesa Recent e o clone CI-1086-22-75, enquanto o segundo foi selecionado da autofecundação do clone C-367-2260. Exceto C-1750-1595, todos os demais clones incluídos na genealogia da cultivar BRS Ana (Figura 1) foram desenvolvidos por Delorge Mota da Costa.

As sementes sexuais da população híbrida que deu origem à cultivar BRS Ana foram semeadas sob telado, em 2000, na Embrapa Clima Temperado, obtendo os primeiros tubérculos para formar a primeira geração de seleção. O processo de seleção compreendeu quatro gerações efetuadas no período de 2001 a 2003, nos campos experimentais de colaboradores da Embrapa Transferência de Tecnologia - Escritório de Negócios de Canoinhas, SC.

Em 2004 e 2005, ainda como clone experimental, a cultivar BRS Ana foi submetida a ensaios comparativos em Canoinhas-SC; Pelotas-RS, CuritibaPR e Lapa-PR. Finalmente, em 2006 e 2007, a cultivar BRS Ana foi submetida a ensaios de valor de cultivo e uso (VCU), utilizando como testemunhas as cultivares Asterix e Agata, em ambientes distintos (Canoinhas-SC, outono e primavera; Pelotas-RS, outono e primavera; Brasília-DF, estação da seca). Nestes ensaios e na caracteriza- ção morfológica e molecular, a cultivar BRS Ana demonstrou distinguibilidade, homogeneidade e estabilidade fenotípica e genética. Concomitantemente e também posteriormente a cultivar BRS Ana foi validada junto a produtores do sul do país, assim como foi realizada a multiplicação de sementes.

\section{DESCRIÇÃO VARIETAL}

A descrição de planta e tubérculos da cultivar BRS Ana foi realizada em campos de avaliação conduzidos em Pelotas-RS (Figura 2).

Plantas (Figura 2A): plantas grandes, com hábito de crescimento ereto, altas, com folhagem fechada e maturidade tardia, em torno de 110 a 120 dias após o plantio ( 7 a 10 dias mais tardia que a cultivar Asterix).

Hastes: vigorosas, com pigmentação de antocianina intermediária na base e com asas retas.

Folhas (Figura 2B): inserção aguda, moderadamente aberta e com pigmentação na nervura principal.

Folíolos: tamanho e largura médios, raramente coalescentes e ondulação débil nas bordas, com frequência moderadamente alta de folíolos secundários.

Flores (Figura 2C): inflorescências abundantes com pedúnculos longos e pigmentados. Corola: azul púrpura, com intensidade de pigmentação moderada na parte interna. Frutos: alta frequência no campo.

Tubérculos (Figura 2D): formato oval, película vermelha e levemente áspera, olhos rasos, polpa branca, dormência média.

Brotos (Figura 2E): formato cilíndrico largo e ápice fechado, base de coloração vermelho-púrpura média e pouca pubescência, primórdios radiculares de intensidade média, com brotações laterais de comprimento mediano.

\section{DESEMPENHO AGRONÔMICO}

O desempenho agronômico da cultivar BRS Ana foi mais destacado em ensaios de outono no ecossistema subtropical, em Pelotas-RS e Canoinhas-SC (Tabela 1). Nestas condições, a cultivar BRS Ana apresentou rendimento total e rendimento de tubérculos graúdos (diâmetro transversal maior que 45 $\mathrm{mm}$ ) maiores que a cultivar Asterix (24,3 e 39,4\%, respectivamente). A percentagem de tubérculos graúdos e o peso médio de tubérculo da cultivar BRS Ana também foram maiores que da cultivar Asterix (42,9\% e 39,9\%, respectivamente).

No cultivo de primavera, a cultivar BRS Ana não diferiu significativamente da cultivar Asterix em nenhum dos componentes de rendimento (Tabela 1). Comportamento semelhante foi observado no plantio da época da seca no ecossistema tropical, exceto pelo fato da cultivar BRS Ana ter apresentado menor percentagem de tubérculos graúdos e peso médio de tubérculos que a cultivar Asterix.

Em testes de validação junto a lavouras de produtores do município de São Lourenço do Sul-RS, em dois períodos de plantio, a cultivar BRS Ana foi comparada às cultivares Baronesa e Asterix. No outono, tanto em rendimento de tubérculos graúdos, quanto em percentagem de tubérculos graúdos, a cultivar BRS Ana (18,8 e 38,8 $\mathrm{tha}^{-1}$, 65, 1 e $77,4 \%$ da produção total, respectivamente nas lavouras 1 e 2) foi claramente superior às cultivares Baronesa (6,6 e $25,8 \mathrm{t} \mathrm{ha}^{-1}, 33,8$ e $67,1 \%$ ) e Asterix (10,8 e 33,3 t ha h $^{-1}, 46,0$ e $\left.67,7 \%\right)$. No entanto, na primavera, a cultivar BRS Ana apresentou menor rendimento de tubérculos graúdos que as cultivares 

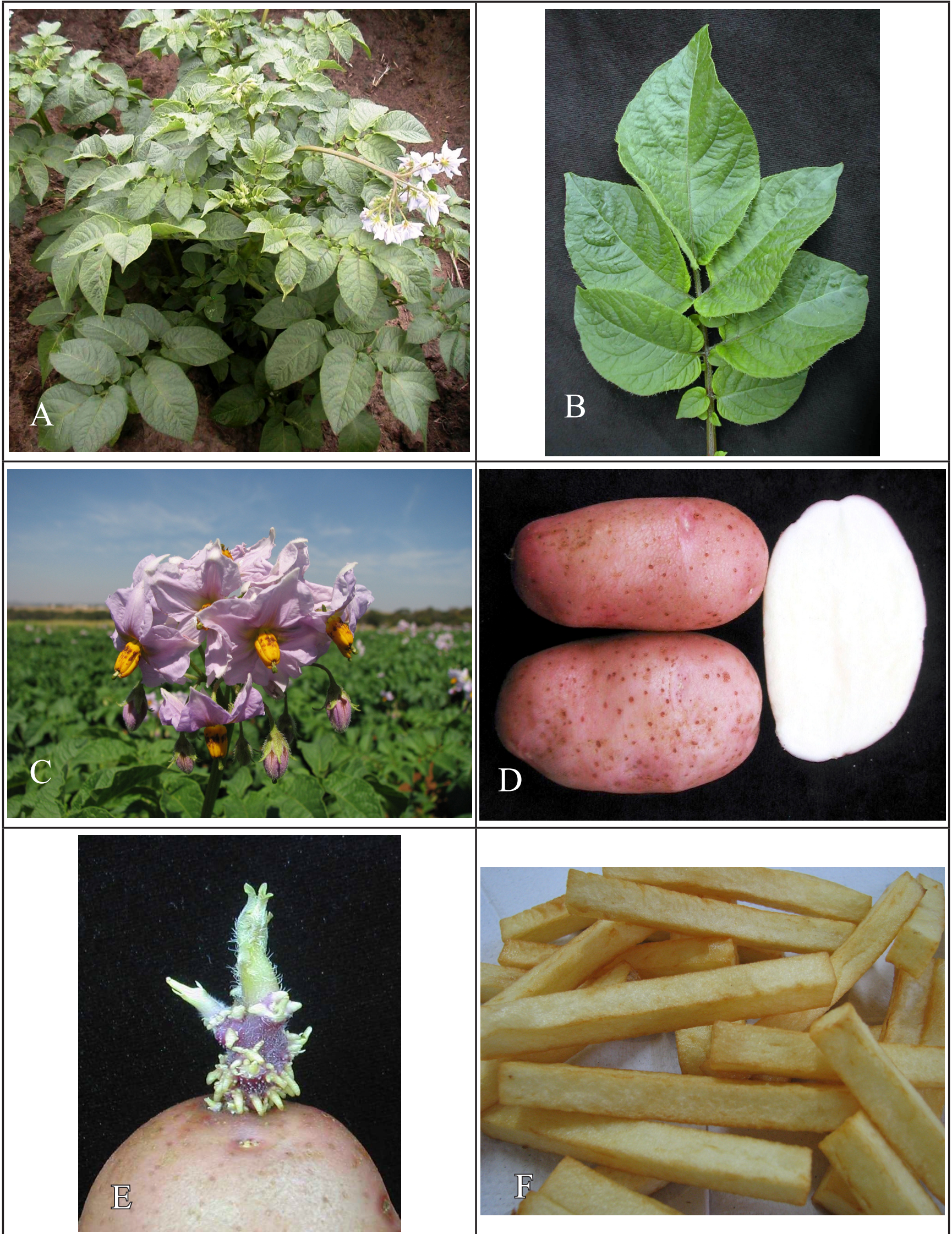

Figura 2. Cultivar BRS Ana: (A) planta inteira, (B) folha composta, (C) flores, (D) aparência externa e polpa dos tubérculos, (E) broto e (F) palitos fritos [cultivar BRS Ana: (A) plant, (B) compound leaf, (C) flowers, (D) tuber external appearance and flesh, (E) sprout and (F) French fries]. Pelotas, Embrapa Clima Temperado, 2010. 
Baronesa e Asterix na lavoura 1 (10,2, 16,4 e $14,7 \mathrm{t} \mathrm{ha}^{-1}$, respectivamente) e similar na lavoura $2(25,0,24,5$, e 26,6 $\mathrm{t} \mathrm{ha}^{-1}$, respectivamente).

\section{CARACTERÍSTICAS DE QUALIDADE DE TUBÉRCULOS E USO}

Peso específico - $\mathrm{Na}$ média dos ecossistemas, o peso específico da cultivar BRS Ana foi superior à da cultivar
Asterix (Tabela 1). Individualizado por ecossistema e época de cultivo, o peso específico da cultivar BRS Ana foi estatisticamente maior que o da cultivar Asterix na primavera, ecossistema subtropical, e no cultivo da seca, ecossistema tropical. Não houve diferença significativa no cultivo de outono, ecossistema subtropical.

Incidência de defeitos nos tubérculos - No ecossistema tropical, em Brasília-DF, não foram observadas desordens de origem fisiológica nos tubérculos da cultivar BRS Ana, em experimento conduzido durante a estação seca. No ecossistema subtropical, a cultivar BRS Ana tampouco apresentou ocorrência de embonecamento e coração oco, em nenhum dos períodos de cultivo. Ao contrário, as cultivares Asterix e Agata mostraram 1,6 e 3,3\% de tubérculos embonecados, respectivamente, no cultivo de outono. Além disso, a cultivar Agata apresentou 1,6\% de tubérculos com coração oco no outono e, a cultivar Asterix, 3,3\% dos tubérculos

Tabela 1. Produção e qualidade de tubérculos das cultivares de batata BRS Ana, Asterix e Agata nos ecossistemas subtropical (Pelotas-RS e Canoinhas-SC) e tropical (Brasília-DF) do Brasil [tuber yield and quality of potato cultivars BRS Ana, Asterix and Agata in subtropical and (Pelotas-RS and Canoinhas-SC) tropical (Brasília-DF) ecosystems of Brazil]. Pelotas, Embrapa Clima Temperado, 2010.

\begin{tabular}{|c|c|c|c|c|c|c|}
\hline \multirow{2}{*}{ Caráter } & \multicolumn{4}{|c|}{ Ecossistema subtropical } & \multirow{2}{*}{\multicolumn{2}{|c|}{$\frac{\text { Ecossistema tropica }}{\text { Secas } / \mathbf{2 0 0 7}}$}} \\
\hline & Outono/2 & 2006 & Primaver: & $1 / 2006$ & & \\
\hline BRS Ana & 31,2 & $a^{*}$ & 42,1 & $\mathrm{a}$ & 33,8 & $\mathrm{a}$ \\
\hline Asterix & 25,1 & $\mathrm{~b}$ & 40,1 & a & 32,0 & a \\
\hline Agata & 17,4 & $\mathrm{c}$ & 39,3 & $\mathrm{a}$ & 19,4 & $\mathrm{~b}$ \\
\hline \multicolumn{7}{|c|}{ Produção de tubérculos graúdos ${ }^{1}\left(t\right.$ ha $\left.^{-1}\right)$} \\
\hline BRS Ana & 23,7 & $\mathrm{a}$ & 29,6 & $\mathrm{a}$ & 19,0 & $\mathrm{a}$ \\
\hline Asterix & 17,0 & $\mathrm{~b}$ & 28,6 & a & 18,8 & a \\
\hline Agata & 9,9 & c & 24,5 & $\mathrm{a}$ & 11,3 & $\mathrm{a}$ \\
\hline \multicolumn{7}{|c|}{ Percentagem de tubérculos graúdos } \\
\hline BRS Ana & 55,6 & $\mathrm{a}$ & 53,4 & $\mathrm{a}$ & 21,2 & $\mathrm{~b}$ \\
\hline Asterix & 38,9 & $\mathrm{~b}$ & 46,1 & $\mathrm{a}$ & 31,2 & $\mathrm{a}$ \\
\hline Agata & 35,1 & $\mathrm{~b}$ & 39,4 & $\mathrm{a}$ & 31,2 & $\mathrm{a}$ \\
\hline \multicolumn{7}{|c|}{ Peso médio (g) } \\
\hline BRS Ana & 108,4 & $\mathrm{a}$ & 76,7 & $\mathrm{a}$ & 62,8 & $\mathrm{~b}$ \\
\hline Asterix & 78,0 & $\mathrm{~b}$ & 78,6 & $\mathrm{a}$ & 70,4 & $\mathrm{a}$ \\
\hline Agata & 60,4 & $\mathrm{c}$ & 70,7 & $\mathrm{a}$ & 71,2 & $\mathrm{a}$ \\
\hline \multicolumn{7}{|c|}{ Peso específico } \\
\hline BRS Ana & 1,086 & $\mathrm{a}$ & 1,088 & $\mathrm{a}$ & 1,109 & $\mathrm{a}$ \\
\hline Asterix & 1,085 & $\mathrm{a}$ & 1,077 & $\mathrm{~b}$ & 1,100 & $\mathrm{~b}$ \\
\hline Agata & 1,076 & $\mathrm{~b}$ & 1,062 & $\mathrm{c}$ & 1,077 & $\mathrm{c}$ \\
\hline \multicolumn{7}{|c|}{ Matéria seca (\%) } \\
\hline BRS Ana & 19,7 & $\mathrm{a}$ & 24,8 & $\mathrm{a}$ & 23,1 & $\mathrm{a}$ \\
\hline Asterix & 21,3 & $\mathrm{a}$ & 21,5 & $\mathrm{~b}$ & 18,1 & $\mathrm{~b}$ \\
\hline Agata & 17,6 & $\mathrm{~b}$ & 17,9 & $\mathrm{c}$ & 16,3 & $\mathrm{c}$ \\
\hline \multicolumn{7}{|c|}{ Açucares redutores ${ }^{2}(\%)$} \\
\hline BRS Ana & 0,10 & $\mathrm{a}$ & 0,03 & $\mathrm{a}$ & - & \\
\hline Asterix & 0,02 & $\mathrm{a}$ & 0,04 & $\mathrm{a}$ & - & \\
\hline Agata & 0,13 & $\mathrm{a}$ & 0,06 & $\mathrm{a}$ & - & \\
\hline
\end{tabular}

Médias seguidas pela mesma letra na coluna não diferem significativamente entre si, teste de Tukey, $\mathrm{p} \leq 0,05$ (means followed by the same letter in the column did not differ significantly from each other, Tukey's test, $p \leq 0,05) ;{ }^{1}$ Tubérculos graúdos: tubérculos com diâmetro transversal superior a $45 \mathrm{~mm}$ (large tubers: tubers with transversal diameter larger than $45 \mathrm{~mm}$ ); ${ }^{2} \mathrm{O}$ valor máximo aceitável é abaixo de $0,12 \%$ (the maximum acceptable value is below $0.12 \%$ ) 
Tabela 2. Qualidade de fritura de palitos das cultivares de batata BRS Ana, Asterix e Agata produzidas nos ecossistemas subtropical (Pelotas-RS) e tropical (Brasília-DF) do Brasil [frying quality of French fries of potato cultivars BRS Ana, Asterix and Agata produced in subtropical (Pelotas-RS) and tropical (Brasília-DF) ecosystems of Brazil]. Pelotas, Embrapa Clima Temperado, 2000-2010.

\begin{tabular}{|c|c|c|c|c|c|c|}
\hline \multirow{2}{*}{ Caráter } & \multicolumn{4}{|c|}{ Ecossistema subtropical } & \multirow{2}{*}{\multicolumn{2}{|c|}{$\frac{\text { Ecossistema tropical }}{\text { "Seca/07" }}$}} \\
\hline & \multicolumn{2}{|c|}{ Outono/06 } & \multicolumn{2}{|c|}{ Primavera/06 } & & \\
\hline \multicolumn{7}{|l|}{$\operatorname{Cor}^{1}$} \\
\hline BRS Ana & 2,15 & $\mathrm{~b}$ & 2,11 & $\mathrm{c}$ & 2,52 & $\mathrm{c}$ \\
\hline Asterix & 1,28 & $\mathrm{c}$ & 3,99 & $\mathrm{~b}$ & 4,23 & $\mathrm{~b}$ \\
\hline Agata & 7,32 & $a^{*}$ & 6,30 & $\mathrm{a}$ & 6,90 & $\mathrm{a}$ \\
\hline \multicolumn{7}{|c|}{ Aparência externa $^{2}$} \\
\hline BRS Ana & 4,84 & $\mathrm{~b}$ & 7,88 & $\mathrm{a}$ & 4,03 & $\mathrm{ab}$ \\
\hline Asterix & 7,07 & $\mathrm{a}$ & 7,32 & $\mathrm{a}$ & 5,62 & $\mathrm{a}$ \\
\hline Agata & 2,35 & $\mathrm{c}$ & 2,54 & $\mathrm{~b}$ & 2,20 & $\mathrm{~b}$ \\
\hline \multicolumn{7}{|l|}{ Textura $^{3}$} \\
\hline BRS Ana & 5,95 & $\mathrm{~b}$ & 7,58 & $\mathrm{a}$ & - & - \\
\hline Asterix & 6,95 & $\mathrm{a}$ & 6,30 & $\mathrm{~b}$ & - & - \\
\hline Agata & 2,21 & $\mathrm{c}$ & 1,67 & $\mathrm{c}$ & - & - \\
\hline \multicolumn{7}{|c|}{ Residual de gordura ${ }^{4}$} \\
\hline BRS Ana & 1,84 & $\mathrm{c}$ & 1,50 & $\mathrm{~b}$ & 4,15 & $\mathrm{~b}$ \\
\hline Asterix & 4,35 & B & 1,77 & $\mathrm{~b}$ & 5,15 & $a b$ \\
\hline Agata & 7,23 & $\mathrm{a}$ & 4,22 & $\mathrm{a}$ & 7,48 & $\mathrm{a}$ \\
\hline \multicolumn{7}{|c|}{ Sabor amargo ${ }^{5}$} \\
\hline BRS Ana & 1,73 & $\mathrm{~b}$ & 1,66 & $\mathrm{~b}$ & 3,25 & $\mathrm{a}$ \\
\hline Asterix & 1,92 & $\mathrm{~b}$ & 1,36 & $\mathrm{~b}$ & 3,43 & $\mathrm{a}$ \\
\hline Agata & 2,27 & $\mathrm{a}$ & 2,76 & $\mathrm{a}$ & 3,00 & $\mathrm{a}$ \\
\hline \multicolumn{7}{|l|}{ Geral $^{6}$} \\
\hline BRS Ana & 7,05 & $\mathrm{~b}$ & 7,91 & $\mathrm{~b}$ & 3,25 & $\mathrm{ab}$ \\
\hline Asterix & 7,72 & $\mathrm{a}$ & 8,03 & $\mathrm{~b}$ & 3,43 & $\mathrm{~b}$ \\
\hline Agata & 1,42 & c & 4,04 & $\mathrm{a}$ & 3,00 & $\mathrm{a}$ \\
\hline
\end{tabular}

* Médias seguidas pela mesma letra na coluna não diferem significativamente entre si, teste de Tukey, $\mathrm{p} \leq 0,05$ (means followed by the same letter in the column did not differ significantly from each other, Tukey's test, $\mathrm{p} \leq 0,05$ ); Cor: $1=$ clara, $9=$ escura (color: $1=$ light, $9=$ dark); ${ }^{2}$ Aparência externa: $1=$ péssima, $9=$ excelente (external appearance: $1=$ poor, $9=$ excellent); ${ }^{3}$ Textura externa: $1=$ firme, $9=$ mole (external texture: $1=$ firm, $9=$ soft); ${ }^{4}$ Residual de gordura: $1=$ baixo, $9=$ alto (residual fat: $1=$ low, $9=$ high); ${ }^{5}$ Sabor amargo: $1=$ não perceptível, $9=$ forte (bitter flavor: $1=$ not noticeable, $9=$ strong); ${ }^{6}$ Qualidade geral: $1=$ péssima, $9=$ ótima (general quality: $1=$ poor, $9=$ excellent).

com o mesmo problema na primavera. A cultivar BRS Ana foi ligeiramente mais suscetível $(6,6 \%)$ à rachadura do que Asterix (5,0\%) no cultivo de outono, ecossistema subtropical. A suscetibilidade à mancha ferruginosa na cultivar BRS Ana foi mais alta na primavera.

Características de fritura - Os palitos fritos obtidos dos tubérculos da cultivar BRS Ana (Figura 2F) foram significativamente mais escuros no outono e mais claros na primavera, ecossistema subtropical, assim como
(Tabela 2).

Ressalta-se ainda que a concentração de gordura nos palitos fritos da cultivar BRS Ana foi significativamente menor para tubérculos obtidos na primavera que para aqueles obtidos no outono, ecossistema subtropical (Tabela 2). Em termos de sabor, não houve diferença significativa entre palitos fritos das cultivares BRS Ana e Asterix (Tabela 2). $\mathrm{Na}$ avaliação geral, os palitos fritos da cultivar BRS Ana foram estatisticamente similares aos da cultivar Asterix para o cultivo de outono, quando os tubérculos são colhidos no inverno, ecossistema subtropical, e para o cultivo da seca, ecossistema tropical (Tabela 2).

Avaliações sensoriais - Em testes sensoriais, a cultivar BRS Ana mostrouse adequada à fritura à francesa, comparando-se à cultivar Asterix (Tabela 2). A cor dos palitos fritos da cultivar BRS Ana foi mais clara que das cultivares testemunhas no cultivo de primavera no ecossistema subtropical e no cultivo da seca no ecossistema tropical, e mais escura do que a cultivar Asterix (testemunha utilizada para fritura) no outono do ecossistema subtropical. Nos testes de cocção e assada (dados não apresentados), a cultivar BRS Ana apresentou boa aptidão, mostrando-se também semelhante à cultivar Asterix. Em conjunto, esses resultados indicam o duplo propósito da BRS Ana, isto é, batata para consumo de mesa e processamento industrial na forma de palitos fritos.

Características bioquímicas e nutricionais - Nos dois ecossistemas, a cultivar BRS Ana apresentou elevados valores de peso específico e conteúdo de matéria seca (Tabela 1). Exceto no outono do ecossistema subtropical, nos demais experimentos a superioridade da cultivar BRS Ana sobre a cultivar Agata foi significativa $(p \leq 0,05)$. O teor de açúcares redutores da cultivar BRS Ana foi numericamente mais elevado em termos absolutos no outono do ecossistema subtropical que aquele observado para a cultivar Asterix, mas não foi significativamente superior (Tabela 1).

Uso - A cultivar BRS Ana é mais adequada para fritura na forma de palitos, tanto na preparação doméstica, quanto no processamento industrial. $\mathrm{O}$ formato e tamanho dos tubérculos, teor 
de matéria seca e potencial produtivo da cultivar BRS Ana são caracteres que favorecem a sua utilização pela indústria de palitos pré-fritos congelados. O uso na fabricação de flocos é outra potencialidade desta cultivar.

\section{REAÇÃO A DOENÇAS}

A cultivar BRS Ana é moderadamente suscetível à requeima (Phytophthora infestans) e canela preta e podridão mole (Pectobacterium sp.), além de moderadamente resistente à pinta preta (Alternaria solani). Ainda assim, pulverização rotineira de fungicidas pode ser necessária para prevenir ataques sérios de requeima e pinta preta. Apresenta ainda baixa degenerescência de sementes por viroses, conferida pela resistência moderada ao vírus Y da batata (Potato virus $Y$ - PVY) e ao vírus do enrolamento da folha da batata (Potato leafroll virus - PLRV).

\section{MANEJO}

Embora o número de estudos sobre o manejo da cultivar BRS Ana seja ainda limitado, tem sido observada boa resistência da cultivar ao herbicida Metribuzin em aplicações seguindo o rótulo do produto. $\mathrm{O}$ hábito ereto e $\mathrm{o}$ tamanho grande de folhagem fazem com que as plantas da cultivar BRS Ana sejam boas competidoras com as plantas espontâneas após o fechamento das linhas, durante a fase de enchimento dos tubérculos até a senescência.

Quanto à adubação, a cultivar BRS
Ana tem apresentado requerimento de cerca da metade do nitrogênio recomendado para a cultura da batata no Rio Grande do Sul e em Santa Catarina (dados não apresentados). Adições de nitrogênio na dose usualmente recomendada para batata (Sociedade, 2004) no plantio e em cobertura estendem o ciclo vegetativo, retardando a senescência das plantas e possivelmente aumentando a indesejável acumulação de açúcares redutores nos tubérculos. Isso é especialmente verdadeiro no cultivo de outono do sul do país (plantio de fevereiro/ março), devido à queda nas temperaturas na época de colheita ou até mesmo em pós-colheita, já que o frio induz à acumulação de açúcares redutores nos tubérculos. Portanto, a qualidade de fritura em relação à cor do produto pode ser prejudicada.

O período de dormência dos tubérculos da cultivar BRS Ana é semelhante ou cerca de cinco dias mais longo que o da cultivar Asterix, podendo-se utilizar o mesmo manejo de quebra de dormência utilizado para a cultivar Asterix.

No ecossistema subtropical, a tuberização é mais tardia na primavera, o que sugere ser muito importante antecipar o plantio neste período.

\section{DISPONIBILIDADE}

Informações sobre batata-semente podem ser obtidas junto à Embrapa Transferência de Tecnologia, EN-Canoinhas, Rodovia BR 280, km 219, C. Postal 317, CEP 89460-000 CanoinhasSC, fone/fax (47) 3624-0127, e-mail: encan.snt@embrapa.br. Esta cultivar está registrada sob o número 21822 e protegida sob o certificado número 01082, em nome da Embrapa, no Ministério de Agricultura, Pecuária e Abastecimento.

\section{AGRADECIMENTOS}

Os autores agradecem ao $\mathrm{CNPq}$, pelas bolsas concedidas, e à FAPERGS (PROCOREDES), pelo suporte financeiro parcial aos testes de validação em São Lourenço do Sul-RS.

\section{REFERÊNCIAS}

DANIELS J; PEREIRAAS. 2004. Resistência de genótipos de batata ao vírus do enrolamento da folha da batata (PLRV) e ao vírus Y (PVY). Horticultura Brasileira 22: 521-524.

FSB COMUNICAÇÕES. 2006. Bem Brasil Alimentos. Batata Show 6: 32-33.

MELO PE. 1999. Cultivares de batata potencialmente úteis para processamento na forma de fritura no Brasil e manejo para obtenção de tubérculos adequados. Informe Agropecuário 20: 112-119.

PEREIRAAS. 2003. Melhoramento genético. In: PEREIRA AS; DANIELS J (eds). O cultivo da batata na região Sul do Brasil. Pelotas: Embrapa Clima Temperado; Brasília: Embrapa Informação Tecnológica. p. 105-124.

PEREIRA AS; CAMPOS AD. 1999. Teor de açúcares em genótipos de batata (Solanum tuberosum L.). Ciência Rural 29: 13-16.

PEREIRA AS; COSTA DM. 1998. Análise da estabilidade de produção de genótipos de batata no Rio Grande do Sul. Pesquisa Agropecuária Brasileira 33: 405-409.

SOCIEDADE BRASILEIRA DE CIÊNCIA DO SOLO. 2004. Comissão de Química e Fertilidade do Solo. Manual de adubação e calagem para os Estados do Rio Grande do Sul e de Santa Catarina. 10. ed. Porto Alegre: SBCS/CQFS. 400p. 